\title{
Report on the Sponge Fishery of Florida and the Artificial culture of Sponges.
}

\author{
(Prepared at the request of the Colonial Office, with a view to the introduction \\ of Sponge Culture in the Bahamas.)
}

By

E. J. Allen, B.Sc.,

Hon. Secretary of the Marine Biological Association, and Director of the Plymouth Laboratory.

\section{SUMMARY.}

I. The Florida Sponge Fishert.-History of the Fishery. Kinds of sponges taken. Relative value of sponges. Methods of procuring sponges. Curing the sponges. Sponge grounds reduced in value through over-fishing.

Sponge Culture Experiments, - Historical.

Experiments of Buccich.-Description of apparatus used, and manner in which the experiments were conducted. Buccich concluded that sponge cuttings would grow to marketable size in seven years.

Experiments in Florida. - Sponge cuttings said to grow more rapidly, increasing to from four to six times their original size in six months, when placed under favourable conditions.

Memorandum by Mr. Benedict, of U.S. National Museum,-Sponge culture experiments do not appear to have been tried to any great extent. Fishermen opposed to anything of the kind as likely to lead to monopoly, and the cutting off their means of subsistence.

Would Sponge-culture by Cutrings be Profitable ?-Marenzeller points out that this would depend on whether pieces of a sponge would in a given time together attain a greater weight than the original sponge would have reached if left undisturbed.

Suggested Experiments. - Suggestions by Mr. Bidder (see below). Fishing by means of divers, or dredging, should be tried in deeper water.

II. Note on Projects for the Improvement of Sponge-Fisheries. By Mr. George Bidder.

A. There appears no reason yet to suppose that the yield of a sponge-fishery will be increased by planting cuttings, unless these are placed in more advantageous positions than the original sponges. Such advantage may probably be obtained by attaching either cuttings or small sponges to canes or tiles, disposed on iron hurdles standing some feet from the sea-bottom. No certain statement, however, can be made with regard to any project, until there has been effected a series of accurate observations on the natural growth of the sponge of commerce. 
B. Sponges could probably be transported alive from the Mediterranean to the Bahamas, but it is not certain that even if they bred freely, their progeny would maintain the superior character of the parents.

C. There is no special breeding season for sponges.

APPENDIX.-Rate of Growth of Sponges.

The Florida Sponge Fishery.*-It was not until the year 1850 that the attention of American sponge merchants was directed to the fact that the reefs of South Florida possessed an abundant growth of sponges. Previous to that time, all sponges sold in America had been obtained from the Mediterranean or the Bahamas. When, however, the true value of the Florida sponges was once realised, an important industry grew rapidly, the island of West Key and the town of Apalachicola being at the present time chiefly interested in the promotion of the fishery.

In Florida, as in the Bahamas, five principal grades of sponges are recognised. The most valuable of these is the sheepswool sponge, which is regarded by naturalists as a variety of Hippospongia equina, the horse-sponge and Venetian bath sponge of the Mediterranean. The representative in America waters of Euspongia officinalis, the Levant toilet sponge and the Turkey cup sponge, the most valuable kinds found in the East, is the glove sponge, which is, however, the least valuable of the American grades. The grades intermediate in value between the sheepswool and the glove sponges are the velvet, another variety of Hippospongia equina, the yellow, and hard-head sponges, which may belong to the same species as the Mediterranean Zimocca sponge (Euspongia zimocca), and the grass sponge (Spongia graminea, possibly a variety of Euspongia officinalis), a grade of little value.

By far the most costly sponges in the market are those from the Mediterranean, the sheepswool sponges of the Bahamas and Florida being regarded as the next in quality. Of the latter, the Florida sponges are said to be superior to those sent from the Bahamas, being supposed to possess a somewhat finer texture, and a more regular and compact mode of growth. The irregularity of shape of the Bahama sponges is stated to be due to the irregular nature of the bottom on which they grow. $\dagger$

The method by which the sponges are procured in Florida is similar to that practised in the Bahamas, but differs essentially from the usual

* The following account has been compiled, for the most part, from an article by Rathbun in "The Fishery Industries of the United States" (Section V. vol. 2, p. 819), published by the U.S. Commission of Fish and Fisheries, Washington, 1887. The discussion of the question by Dr. Juan Vilaro [Esponjicultura cubana, Revista de Pesca Maritima VII. Madrid, 1891], was also consulted; it is compiled chiefly from the American Reports.

† The method of preparation of Bahama sponges is also stated to be inferior to that practised in Florida. 
Mediterranean mode of fishing. In the latter case the sponges are generally obtained by divers from depths of from 15 to 20 fathoms, the men working without a diving dress, using large stones, which they hold at arm's length in front of them, to carry them to the bottom. They usually remain under water about two minutes. In America, on the other hand, sponges are taken in water of from 3 to 6 fathoms, or even shallower, by means of a three-pronged hook fixed at the end of a pole, men working the poles from small boats. The sponges are seen from the surface with the aid of a "sponge-glass," which is generally a wooden bucket painted a dark colour inside, and with the bottom replaced by a sheet of glass. When the glass is plunged below the surface of the water, the effect of the surface ripples is removed, and by looking through the bucket a clear view of the sea-bottom can be obtained even at considerable depths. As soon as a sponge is seen it is taken by means of the hooks. At the end of a day's fishing, the small boats, each of which is usually occupied by two men, return with their catches to the sponging vessel, which has been lying near all day, and the sponges are placed on board. Some of these vessels remain on the fishing grounds for from one to three months, whilst others return to port at the end of a week or fortnight only. It is generally usual, however, for the vessels to take their catch every week to the "crawls"-enclosures of stakes 8 or 10 feet square, situated in water 2 to 3 feet deep-in which the sponges are cured. The process of curing consists in allowing the animal portion of the sponge to rot, and then clearing it away by squeezing and beating. As much of the water as possible is pressed out, and the sponges then strung on rope yarns, and hung up to bleach and dry. The only other processes to which they are subjected before being placed upon the market are "liming" and trimming, but both of these are carried out after they have passed out of the hands of the fishermen into those of the dealers. The "liming" consists in dipping the sponges in a weak solution of lime in sea-water, and subsequently drying them, a treatment which adds to their value by giving them a bright yellow colour. This process requires to be very carefully performed, as too much lime is liable to injure the tissue of the sponge.

When sponge-fishing was first practised on a large scale in Florida, only the larger sponges were taken, but in consequence of the amount of fishing which was carried on, the number of large sponges became insufficient to supply the demand, and the smaller ones were gathered to make up the requisite quantity. It became evident, however, that the value of the grounds would soon become considerably reduced, and those interested in the matter began to consider the possibility of increasing the number of sponges by attempting their artificial 
cultivation. Unfortunately, however, up to the present time, the matter does not appear to have been carried beyond a very elementary experimental stage.

Sponge Culture Experiments.-The statement that detached sponges were capable of fixing themselves and continuing their growth, was first recorded in 1785 by Filippo Cavolini, his account being based upon experiments carried out in the Bay of Naples. It was not, however, until the year 1862 that attention was drawn by Professor Oscar Schmidt to the fact that portions of a sponge would also fix and grow, and the possibility of its application to the production of sponges on a commercial scale pointed out.

Experiments of BuCCICH.-In consequence of the opinion expressed by Professor Schmidt, " that if a perfectly fresh sponge is cut in suitable pieces, and if these pieces, properly protected, are again placed in the sea, they will grow and finally develop into complete sponges," a number of experiments were made during 1863-1872, at a station established on the bay of Socolizza, at the north-eastern point of the island of Lesina. This establishment was closed in 1872 , on account of the hostility of the native fishermen, who continually interfered with the growing sponges. An account of these experiments has been given by Dr. Emil von Marenzeller,* from the original notes of Signor Gregor Buccich, who was in charge of the establishment. The experiments seem to show that for European sponges cuttings, if carefully treated, can be reared successfully until they become of marketable size. From the account given, it appears that for making sponge-cuttings the most favourable time is during the winter months, as in cool weather there is less tendency for the sponges to suffer from detachment and exposure to air. The best localities are sheltered bays, with pure sea-water as free as possible from mud. The sponges from which the cuttings are to be made require very careful treatment, and the method finally adopted by Buccich was as follows: The sponges having been obtained either with tongs or a drag-net, and the injured portions, as far as possible, removed, they are fixed by means of wooden pegs to the inner side of a sort of fish-box, which is towed behind the boat. It is better, especially in warm weather, to leave the sponges for a little time in this box, in order to see whether or not putrefaction is likely to take place. When it has been ascertained that all the sponges are healthy, the cutting and planting are proceeded with. The cutting is done upon a small board, moistened with sea-water, with a knife having a saw-edge, and the pieces are made so as to measure about an inch each way.

* Die Aufzucht des Badeschwammes aus Theilstücken. Verhandl. der k.k. Zoologischbotanischen Gesellschaft in Wien. Vienna, 1878. Translated in U.S. Fish Commission Report, 1879 ; p. 771. 
Each piece should have as large an area as possible of intact outer skin. Various methods of planting the cuttings were tried. The pieces, especially those with only one cut surface, very soon attach themselves to a suitable base either of stone or wood, if brought into close contact with it. They must, however, in general be fastened in some way to prevent them from being moved about by waves and currents. Amongst other methods tried by Buccich was that of fixing the pieces by means of wooden pegs upon flagstones, in which holes were bored. But in this case the mud and sand on the bottom, and possibly also the excess of light, proved injurious. The apparatus finally adopted consisted of two boards, about 25 inches long and 16 inches broad, kept in a parallel position one above the other by two props placed at a distance apart of about $4 \frac{1}{2}$ inches, and having their opposite ends fixed to the boards. Between the props stones could be put as ballast. Twenty-four holes, at distances of $4 \frac{3}{4}$ inches from each other, were bored in each board, into which the two ends of as many bamboo rods could be fastened, thus forming a kind of vertical grating. Before, however, the bamboo rods were placed in position, the pieces of sponge were fixed to them in the following way: Three holes were made in each rod, at equal distances apart, and each piece of sponge was perforated with a hole sufficiently large for it to be able to slide on the rod. Three pieces of sponge were put on each rod, and supported on wooden pegs placed through the holes in the latter. In order to perforate the sponge-cuttings without injuring them, a trepan about a quarter of an inch wide, kept in rapid motion by a fly-wheel, was used. When the pieces of sponge had been fixed on the rods as described, and the rods placed in position in the frame, the whole was sunk to the bottom and allowed to remain. All wood used in the apparatus was well tarred, in order to prevent the destructive action of boring molluses, and for this purpose it would be advisable, in any future experiments, to construct the apparatus of iron. It was found that if due care had been taken, 90 per cent. of the cuttings developed successfully, and Buccich states that they were found to grow two or three times their original size during the first year. He was of opinion that although some pieces will grow to a considerable size in five years, it would require seven years to raise completely matured sponges fit for the market.

Experiments IN Florida.-It has been maintained, however, that for Florida sponges the rate of growth is considerably quicker than that indicated by these experiments, and the only account yet given of any attempt there made to grow sponges from cuttings appears to confirm this view. This is given by Rathbun, ${ }^{*}$ as follows-

$$
\text { * Loc. cit. p. } 832 .
$$


"The first trials were made at Key West, by the agent of Messrs. Mc Kesson and Robbins, sponge dealers, of New York, who have recently contributed to the U. S. National Museum four specimens of the sheepswool variety, showing the first-fruit of this important work. We have not been able to obtain a detailed report of these experiments, but from a letter written at Key West, and kindly furnished by Messrs. McKesson and Robbins, the following brief account has been prepared-

"The sponges were all raised from cuttings; the localities in which they were planted were not the most favourable for sponge development, and their growth was, therefore, less rapid and perfect than might otherwise have been the case. They were fastened to the bottom, in a depth of about $2 \frac{1}{2}$ feet of water, by means of wires or sticks running through them. The four specimens sent to Washington were allowed to remain down a period of about six months before they were removed. Fully four months elapsed before they recovered from the injury done them in the cutting, which removes the outer 'skin' along the edges of the section, and the actual growth exhibited was for about two months only. The original height of each of the cuttings was about $2 \frac{1}{2}$ inches. One was planted in a cove or bight, where there was little or no current, and its increase in size was very slight. The other specimens were placed in tide-ways, and have grown to from four to six times their former bulk. Two hundred and sixteen specimens in all were planted at the same date, and at the last accounts those that remained were doing finely.

"The chief obstacle to the artificial cultivation of sponges at Key West arises from the fact that the sponge fishermen infest every part of the region where sponges are likely to grow, and there is no legal protection for the would-be culturist against intruders. The enactment of judicious laws bearing upon this subject by the State of Florida, or the granting of special privileges conferring the right to occupy certain prescribed areas for sponge propagation, would undoubtedly tend to increase the annual production of this important fishery."

Unfortunately, these experiments do not appear to have been carried further in Florida, and no reference to their continuation is made in subsequent reports of the U. S. Fish Commission.

Memorandum By Mr. Benedict.-Through the kindness of Professor Brown Goode, it is possible in this connection to add the following memorandum by Mr. James E. Benedict, Assistant Curator of the Department of Marine Invertebrates at the United States National Museum-

"While in Florida several years ago, I inquired particularly into sponge culture. Many people denied that the experiment had ever been successfully tried, showing that it had not been tried to any great extent. I was informed, however, that by raising a sponge nearly to the surface, without lifting it out of the water, and dividing it up, and fastening the pieces to some anchor, and placing them in favourable localities, they grew rapidly. The sponge fisher- 
men, however, are very much opposed to experimenting in this direction, as they believe it can only be successfully carried on when the grounds are parcelled out, which they think would result in monopoly, and cutting off their means of subsistence.

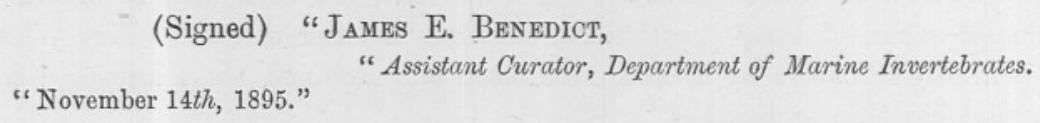

Would Sponge-culture By Cuttings Be Profitable?-To what extent the culture of sponges, after the manner suggested by Schmidt, would be a profitable undertaking, depends largely upon the rate of growth of the cuttings as compared with the rate of growth of uncut sponges. As Dr. von Marenzeller points out, it is questionable "whether it is profitable to cut to pieces a sponge, which uncut would have quicker reached the same size and weight than all the cuttings together in seven years. Under such circumstances, sponge-culture had better be confined to the transformation of flat and, therefore, worthless sponges into round ones, which, though small, would find a ready market. Possibly several, especially misshaped, pieces might be made to grow together, and form larger and better ones."

Suggested Experiments.-Mr. George Bidder, a member of the Marine Biological Association who has been engaged for some years in studying the anatomy and physiology of sponges, and is a recognised authority on these subjects, has kindly furnished some valuable notes upon this point, in addition to a number of suggestions as to various methods for endeavouring to improve sponge fisheries, which are appended to this report.

In addition to the practical proposals made by $\mathrm{Mr}$. Bidder as to the most suitable lines upon which experiments might be carried on, with a view to the improvement of the Bahama sponge industry, it may be suggested also that, in case this has not already been tried, an attempt should be made to obtain sponges in the Bahamas from deeper water, either by the use of the dredge, or with the aid of divers. In the Mediterranean, the sponges found in shallow waters, such as those from which they are obtained in America, are stated to be much coarser and less valuable than those taken from depths of from 15-20 fathoms. According to Hyatt, sponges probably occur in American seas down to a depth of about 30 fathoms, and it is quite possible that an attempt to obtain some of those living at greater depths than the 3-6 fathoms, to which the fishing is at present confined, might yield more valuable material. This could be easily ascertained, when one of H.M. ships, with divers on board, visited the Bahamas, or experiments might be made with the dredge. Sponges obtained by these methods would also be less injured than those taken with the hooks. 